\title{
Concentrator photovoltaic technologies and market: a critical review
}

\author{
Alaeddine Mokri, Mahieddine Emziane \\ Solar Energy Materials and Devices Lab, \\ Masdar Institute of Science and Technology, \\ Masdar City, PO Box 54224, Abu Dhabi, UAE \\ E-mailS: amokri@masdar.ac.ae,memziane@masdar.ac.ae
}

\begin{abstract}
This paper offers an overview about the current status of the concentrator photovoltaic technologies and market. It highlights the potential of this technology to bring the cost of electricity to competitive levels with fossil-fuel based resources. It starts with an overview about the photovoltaic market and then it narrows its scope to describe the concentrator photovoltaic technology (CPV). Then, it goes on quantifying the world CPV capacity based on the latest industry reports released in 2010. In this paper, we estimate the current world operational CPV capacity to be $21 \mathrm{MW}$. This paper also reports a minimum installation cost as low as 3.05 \$/W and a levelised cost of electricity as low as $0.14 \$ / \mathrm{kWh}$. Those are the minimum costs announced in 2010 . One interesting conclusion of this study is that CPV systems with high concentration have a higher economic potential comparatively with low concentration CPV systems.
\end{abstract}

Keywords: solar energy, photovoltaic, concentrator photovoltaics, LCOE, grid parity.

\section{Introduction}

Past and current trends in energy generation, supply and consumption have shown their unsustainability at the economic, social, and more importantly, environment levels. These trends led to the following [1]:

- $\quad$ The current GHG emission levels have not been seen for at least 800000 years.

- By the year 2050, $\mathrm{CO}_{2}$ concentration in the atmosphere will reach 380 part per million which is higher than the upper safe limit (i.e. 350 part per million) for avoiding severe climate change effects [2].

- In the past century, temperature of the planet increased by $0.7^{\circ} \mathrm{C}$ and the sea levels by $20 \mathrm{~cm}$.

- Ice caps are disappearing.

- The International Energy Agency (IEA) expects an increase of 50\% in energy demand by 2030.

- Half of the $\mathrm{CO}_{2}$ emissions from burning fossil fuels over the last 200 years were emitted in the last 30 years.

Without a decisive action, on the top of the facts listed above, increasing energy demand will raise concerns over energy security because of the continuous growth of the world population and economy [3].

The solution to this issue is to use clean renewable energy sources like solar, wind, geothermal, etc. Although these energy sources are abundant and free, their conversion to useful power comes at a higher cost than power from non-renewable sources and makes them less advantageous. Therefore, the main condition for the transition to a renewable energy era is to generate power from renewable sources at competitive costs with power from fossil-fuel based resources. 
Since 2000, global photovoltaic (PV) capacity has been growing at an average rate of $40 \%$ per year to reach 14 Giga Watt in 2008 [3]. Expectedly, the annual photovoltaic capacity will represent $11 \%$ of the global electricity capacity by the year 2050 [3]. This will cancel 2.3 Giga tons of $\mathrm{CO}_{2}$ emissions from the atmosphere [3].

PV energy encompasses a wide range of technologies: silicon, thin films and concentrator photovoltaics (CPV). While silicon modules represent $85-90 \%$ of the global annual market and thin film modules represent $10-15 \%$, CPV modules represent less than $1 \%$ of the global annual market [3]. However, CPV is still emerging and has the highest potential of bringing the LCOE (Levelized Cost of Electricity) down to values that make solar power costcompetitive with conventional sources of electricity [4].

This article offers an overview of the current status of the CPV market and discusses the potential to achieve low LCOE.

\section{Concentrator photovoltaic technology}

A CPV system consists simply of a small solar cell and an optical component to concentrate light on it. Using low-cost optical components with small solar cells instead of large expensive solar cells is a key feature to achieve a low LCOE [5].

By doing some simple math, one can conclude that to generate a $1 \mathrm{~W}$ of electricity, a $25 \%$ efficient solar cell under a 1000 concentration ratio requires 1775 less cell surface than a 14\% efficient cell under no concentration. In the real world, CPV modules using 27\%-36\% efficient multi-junction solar cells are $25 \%$ efficient [4]. This is higher than the efficiency of converting power by using any of the other PV technologies. Comparatively with the other PV technologies, high CPV systems efficiency means that less land is needed to generate a given amount of power; or alternatively, more power can be generated if the same land area is used.

The claims above all depend to a large extent on the solar resource available. For instance, high-concentration CPV modules are economically viable in areas with more than 2200 $\mathrm{kW} / \mathrm{m}^{2}$ year of direct normal irradiance (DNI). Humid regions, areas with cloudy weather, windy areas and spots with an inappropriate topography all may not be suitable places for installing CPV power plants [4].

Based on their concentration ratio and the type of solar cells used, CPV technologies can be classified into three categories:

\subsection{Low-Concentration Photovoltaic (LCPV):}

Systems with a concentration lower than 40 suns fit in this category. These systems use Si solar cells and require passive cooling only to maintain their performance. Due to their large acceptance angle, high-precision tracking might not be required. Today, more than 20 companies are known for supplying LCPV modules.

\subsection{Mid-Concentration Photovoltaic (MCPV):}

This applies to systems with concentration ratios in the range 40-300 suns. These systems use multi-junction cells and may require active cooling. Active cooling is a requirement because typically when the temperature of the solar cells increases, their conversion efficiency goes down. High-precision tracking is also required to convert the maximum of the incident 
sunlight. Based on the CPV Today Industry Report, 3 companies only supply MCPV modules [4].

\subsection{High-Concentration Photovoltaic (HCPV):}

These are systems with concentration ratios in the range 300-2000 suns. These systems require a high capacity heat sink, high-precision tracking and high-performance multijunction solar cells; hence, their high cost. The potential of this technology relies on the very high-efficient multi-junction cells used. The $41.6 \%$ efficiency recorded on a multi-junction cell under concentration in August 2009 by Spectrolab and the $35.6 \%$ efficiency recorded on a solar cell under no concentration by Sharp, both highlight the potential of these CPV systems to achieve high efficiencies [4, 6]. Theoretically, the efficiency of multi-junction solar cells can reach $87 \%$. By using these high-performance cells, module efficiencies above $30 \%$ have been recorded [7]. About 33 companies do supply HCPV modules.

\section{CPV installations worldwide}

The total CPV capacity grew up from few kilowatts installed in 2006, to $1 \mathrm{MW}$ in 2007, to 13 MW in 2008, and unexpectedly to 4 MW only in 2009 because of the world financial crisis. 50 MW capacity was expected to be installed worldwide in 2009 [8]. Nevertheless, 2009 witnessed the announcement of a $60 \mathrm{MW}$ CPV power plant in Taiwan by Ya-Fei Green Energy and Guascor Foton.

Those numbers are much below the potential CPV capacity that can be provided. Today, the world manufacturing capacity of CPV is $1.23 \mathrm{GW}$ and it is expected to reach $2.65 \mathrm{GW}$ by 2012-2013.

Currently, the total operational HCPV capacity is estimated at 20.15 MW distributed among 48 installations worldwide. As for the pre-operational HCPV capacity, it is predicted that 23 installations will be operational to produce $247 \mathrm{MW}$.

For LCPV, the total operational capacity is $0.81 \mathrm{MW}$ and it is distributed among 19 installations worldwide. Fig. 1 lists the CPV companies worldwide and the operational and the preoperational capacity of each one.

\section{Current costs of electricity from CPV systems}

The installed cost is a common criterion for ranking and comparing solar installations. It is the cost of the entire installation divided by the peak-power rating. The installed cost of CPV systems varies from one installation to the other; therefore, many values have been reported in the literature. Based on the CPV today Industry Report 2010, the overall installed cost of HCPV systems in 2010 ranges from $3.05 \$ / W$ to $7.25 \$ / W$; however, for LCPV systems, the installed cost is $5.05 \$ / \mathrm{W}[4]$.

The LCOE is also another useful measure for comparing and ranking solar installations. It is the cost of $1 \mathrm{kWh}$ of energy from the system during its life time. For HCPV systems, the LCOE has been reported to vary between $0.14 \$ / \mathrm{kWh}$ and $0.50 \$ / \mathrm{kWh}$. For LCPV systems, the LCOE has been reported to be $0.24 \$ / \mathrm{kWh}$.

These costs can be brought down by improving the efficiency of the cells, improving their reliability and also lowering the cost of the solar cells [4]. 


\section{Conclusions}

In this paper, we discussed the potential of CPV as a choice for generating clean energy at a low LCOE. The most up-to-date data indicate that the total installed CPV capacity in the world does not exceed $300 \mathrm{MW}$. We have also shown that this is much below the $1.23 \mathrm{GW}$ manufacturing capacity available today.

For HCPV, installation costs as low as $3.05 \$ / \mathrm{W}$ and LCOE as low as $0.14 \$ / \mathrm{kWh}$ have been reported in 2010 based on real data. For LCPV, an installed cost of 5.05 \$/W and LCOE of $0.24 \$$ have been reported. These numbers show that CPV systems with high concentration have a high economic potential comparatively with low concentration CPV systems.

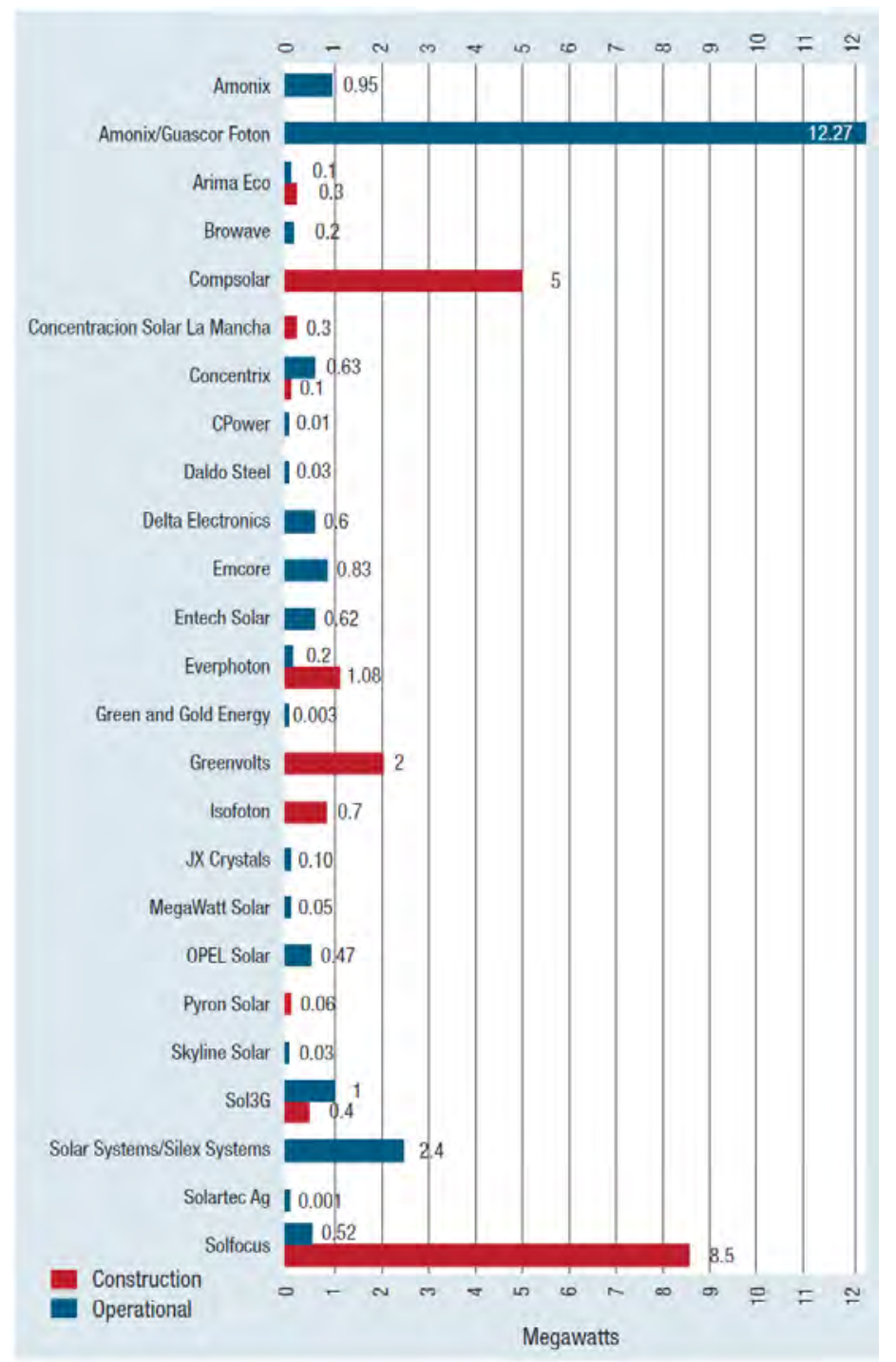

Fig. 1. Pre-operational and operational CPV power generation capacity by company (from reference [4]). 


\section{References}

[1] Trevor M. Letcher, "Future Energy: Improved, sustainable and clean options for our planet." Elsevier, 2008.

[2] K. Rajeshwar, R. McConnell, S. Licht "Solar hydrogen generation toward a renewable energy future", Springer, 2008.

[3] “Technology roadmap: solar photovoltaic energy," International Energy Agency, 2010.

[4] A. Extance, C. Marquez, “The Concentrated Photovoltaics Industry Report 2010,” CPV Today, 2010.

[5] R. A. Sherif, N. H. Karam, R. R. King, D. R. Lillington, "The Path to 1 GW of Concentrator Photovoltaics Using multi-junction Solar Cells," 31 IEEE PVSC pp17-22, 2005; "multi-junction Solar Cells," Nature Photonics 2008.

[6] M. A. Green, K. Emery, Y. Hishikawa and W. Warta, Progress in Photovoltaics: Research and Applications, 2010; 18:346-352.

[7] R. Gordon, G. Kinsey, A. Nayaak, V. Garboushian, “30\% CPV module milestone,” in proceedings of the $6^{\text {th }}$ International Conference on Photovoltaic Systems (CPV-6), pp171, 2010.

[8] S. Kurtz, "Opportunities and Challenges for Development of a Mature Concentrating Photovoltaic Power Industry”, Technical Report NREL/TP-520-43208, Revised November 2009.

[9] D. Friedman, "National solar technology roadmap: concentrator PV”, Management Report NREL/MP-520-41735, June 2007. 